\title{
MOTIVAÇÕES DE CANDIDATOS E VOLUNTÁRIOS NA FUNDAÇÃO CIDADE VIVA
}

\section{MOTIVATIONS OF CANDIDATES AND VOLUNTEERS IN THE CIDADE VIVA FOUNDATION}

\author{
Jéssika Kadidja de Oliveira Medeiros ${ }^{1}$ \\ Carlos Eduardo Cavalcante ${ }^{1}$ \\ Bárbara Stephanie Lira Maciel ${ }^{1}$ \\ Tairine Vieira Ferraz ${ }^{1}$
}

Recebido em: 20/07/2016 Aceito em: 04/07/2017

tairineferraz1@gmail.com
Resumo: O trabalho voluntário é a força das organizações da sociedade civil. Existem diferenças entre o trabalho voluntário e o formal, como remuneração e o tempo destinado às atividades. Logo, teorias motivacionais desenvolvidas numa perspectiva de trabalho formal não devem ser aplicadas a esse grupo. Neste estudo, identificaram-se as motivações dos candidatos a voluntários e dos que já atuam na Fundação Cidade Viva, em João Pessoa, por meio do modelo teórico de Cavalcante (2012). A pesquisa é de natureza quantitativa e para realizá-la, foram manipuladas duas amostras: uma relativa à fase 'expectativas', e a outra, à fase 'entrada'. Na análise dos dados, foram utilizadas estatísticas descritivas. Os resultados revelaram que predominou o perfil altruísta em ambas as fases utilizadas do modelo e que o perfil egoísta foi o menos apresentado pelos respondentes da pesquisa.

Palavras-chave: Trabalho voluntário. Motivação. Motivação no trabalho voluntário.

\begin{abstract}
Volunteering performed by civil society organizations. Distinctions between volunteering and formal work are evident, as the compensation and the time for the performance of activities. Therefore, motivational theories developed from a formal work perspective should not be applied to this group. This study identified motivations presented by candidates for volunteers and current volunteers of the Cidade Viva Foundation in João Pessoa through the theoretical model proposed by Cavalcante (2012). The research is characterized as quantitative, for the accomplishment of the study, two samples were manipulated, one related to the phase 'expectations' and the second to 'entrance'. Data were analyzed using descriptive statistics. Regarding the results, there is a predominance of the altruistic profile in both phases of the model. Still, the selfish profile was the least presented by the survey respondents.
\end{abstract}

Keywords: Volunteering. Motivation. Volunteer motivation.

\footnotetext{
${ }^{1}$ Universidade Federal da Paraíba - UFPB - João Pessoa - Paraíba - Brasil.
} 


\section{INTRODUÇÂO}

Segundo Anheier (2005), as organizações do terceiro setor existem para preencher as 'falhas de mercado' que ocorrem no fornecimento dos bens e dos serviços públicos e privados. Nessa linha de raciocínio, Anheier (2005) assevera que a sociedade precisaria de 'bens públicos puros' - aqueles sobre os quais nenhum direito de propriedade individual pode ser estabelecido, que devem estar disponíveis para todos e ser bem fornecidos pelo Estado ou pelo Setor Público; de 'bens privados puros', aqueles para os quais os direitos de propriedade individual e produção seriam adequados e, por conseguinte, fornecidos pelo Mercado, e os 'bens semipúblicos', que se originariam das falhas de fornecimento desses setores (assimetria de informação, problemas relacionados à confiança, externalidades e custos transacionais), que seriam adequadamente fornecidos pelas organizações do terceiro setor ou sem fins lucrativos.

Umas das muitas formas de organização social do terceiro setor são as Organizações Não Governamentais (ONGs), que Tachizawa (2012) define como instituições de natureza privada (não públicas) sem fins lucrativos. No Brasil, a partir da década de 90, conforme Avritzer (2009), houve a proliferação de ONGs. Segundo o IBGE (2012), existem, aproximadamente, 290 mil instituições do terceiro setor cuja maioria foi criada depois da década de 1980. Nas últimas décadas, o crescimento do terceiro setor e a expansão da atividade voluntária- pesquisas como as de Landim e Scalon (2000) discorrem, por exemplo, sobre o crescimento exponencial do número de voluntários no Brasil - revestem de importância o tema para os estudos organizacionais e implica a necessidade de se refletir sobre as formas como são gerenciados esses tipos de organização.

Autores como Teodósio (2002), Costa (2002), Procopiuck e Meyer Jr. (2011) defendem que teorias que foram desenvolvidas numa perspectiva de trabalho formal não podem ser transpostas de maneira linear e absoluta para a ambiência do voluntariado. Para Drucker (1999), o que torna forte uma organização sem fins lucrativos são as pessoas que trabalham nela e alerta para o fato de que comumente as pessoas não trabalham em ONGs para sobreviver, mas por uma causa. Portanto, o gestor é responsável por manter essa "chama viva" (DRUCKER, 1999, p. 110). Musick e Wilson (2008) asseveram que a motivação desempenha um importante papel nos estudos sobre o voluntariado. O interesse pelos estudos sobre a motivação do trabalho voluntário e a expansão das iniciativas de caráter civil e associativo, segundo Fernandes (1994), ganharam impulso nos anos 70 e se aceleraram na década seguinte.

A atividade voluntária é realizada por cidadãos que doam seu tempo e exercem suas atividades visando intervir na realidade social para beneficiar outra pessoa, grupo ou organização (CAVALCANTE, 2012; COSTA, 2002; SALAMON, 1994). Quando se compara o trabalho voluntário com o trabalho formal, ficam evidentes algumas diferenças, como, por exemplo, a remuneração e o tempo destinado ao desempenho das atividades laborativas. Ao contrário dos trabalhadores formais, os voluntários não recebem aportes financeiros como pagamento para as funções desempenhadas e doam, em média, menos tempo para a atividade voluntária do que para o exercício de um trabalho formal (AZEVEDO, 2007; TRIGUEIRO, 2010; CAVALCANTE, 2012). Considera-se, para fins deste trabalho, que atividade formal é aquela em que uma pessoa dá sua força de trabalho (manual ou 
intelectual) e, a depender do papel que ocupa ou da função que desempenha, é-lhe conferida uma remuneração.

A Fundação Cidade Viva - uma organização sem fins lucrativos, vinculada à Associação Evangélica Primeira Igreja Batista do Bessamar, da cidade de João Pessoa - foi a instituição escolhida para ser pesquisada e está inserida no universo das organizações do terceiro setor que ora se apresenta. Atende a crianças abrigadas ou hospitalizadas, a idosos, a presidiários e a moradores de rua e presta serviços diversos (FUNDAÇÃO CIDADE VIVA, 2013). Sua atuação e repercute sobremaneira na localidade.

Dispõe de um quadro de trinta ministérios e, aproximadamente, 800 trabalhadores voluntários. A escolha da instituição também é motivada pelo grande número de voluntários permanentes que tem. A organização consegue, em eventos, reunir cerca de 1.000 voluntários. No ano de 2015, conseguiu ampliar esse recrutamento para 4.681 inscritos nas atividades (GODSTOCK, 2015; CAVALCANTE, 2013; LEMOS, 2016). Assim, devido aos impactos decorrentes das ações da fundação e à quantidade expressiva de voluntários que tem, essa instituição é um campo fértil para uma pesquisa sobre voluntariado.

Delinear os motivos que levam esse grupo de indivíduos a voluntariar é o que norteia este artigo. Além disso, o fato de a Fundação ter interesse em compreender o que mantém seus voluntários motivados e o que motiva seus pretensos voluntários, por acreditar que a motivação implica a melhoria de problemas como abandono e rotatividade, são fatores que viabilizaram o desenvolvimento desta pesquisa. Problemas como esses são enfrentados por muitas organizações pertencentes ao terceiro setor, e isso traz inúmeras consequências, como a redução da prestação de serviços contínuos e bem qualificados e os gastos relativos a recrutamento, seleção e treinamento de novos voluntários (CHAPMAN e WHITE, 2012; RESS et al., 2010; PICCOLI e GODOI, 2012).

Nesse sentido, o objetivo deste trabalho foi o de investigar as motivações dos atuais voluntários e dos candidatos a essa atividade na Fundação Cidade Viva de João Pessoa, tomando como referência o modelo teórico criado por Cavalcante (2012). É importante salientar que o modelo teórico utilizado neste trabalho foi validado e demonstra evidências fortes de que voluntários em plena atividade e candidatos à atividade são diferentes no que diz respeito à questão da motivação, por isso devem ser pesquisados separadamente. Essa diferença é arbitrária do modelo e teve bons índices na análise confirmatória. $O$ trabalho também poderá contribuir efetivamente para a gestão de voluntários em organizações não governamentais e colabora para se promover discussões a respeito dos modos de gerir o voluntariado como um tema importante a ser discutido em âmbito acadêmico.

No que diz respeito à estrutura, o artigo foi dividido em quatro partes, além desta introdução. No referencial teórico, em que são abordados aspectos relacionados ao trabalho voluntário e à sua motivação, é mais bem detalhado o modelo de análise. Na sequência, apresenta-se a abordagem metodológica que norteia o trabalho e analisam-se os dados coletados e seus resultados. Por fim, apresentam-se as reflexões e as considerações relativas às análises.

Estudos do CEPE [ISSN 1982-6729]. Santa Cruz do Sul, n. 46, p. 166-183, jul./dez. 2017. https://online.unisc.br/seer/index.php/cepe/index 


\section{FUNDAMENTAÇÃO TEÓRICA}

\subsection{Trabalho voluntário}

Conceituar é um ponto de partida indispensável para que a aproximação dos fenômenos que se deseja conhecer aconteça. Ainda que esses fenômenos não sejam estáticos, por meio dos conceitos, pode-se partir de um caminho antes percorrido com o intuito de avançar. Com essa ideia em mente, nesta seção, são revisitadas algumas acepções a respeito do trabalho voluntário.

Das várias conceituações encontradas na literatura e que podem ser atribuídas ao termo 'trabalho voluntário', um estudo desenvolvido pela ONU (2001) utiliza três critérios para defini-lo: o primeiro afirma que esse tipo de trabalho não pode ser realizado com o intuito de obter ganhos financeiros, com a ressalva de que um voluntário poderá ser reembolsado por seus gastos. Entretanto, o valor desse reembolso tem de ser inferior aos valores pagos no mercado de trabalho formal (ONU, 2001). O segundo critério determina que o trabalho voluntário deve ser exercido livremente, sem pressões ou coerções, e o terceiro, que o trabalho voluntário traz benefícios mútuos tanto para quem o executa quanto para quem recebe a ajuda.

Além desses três critérios, a ONU (2001) acresceu duas características que ajudam a conceituar o termo voluntariado. A primeira delas assume que o voluntariado não acontece somente em organizações, sejam elas sem fins lucrativos, governamentais ou privadas, porquanto também podem ser considerados beneficiários amigos, vizinhos ou a sociedade, excluindo-se a família em primeiro grau (ONU, 2001). A segunda afirma que o voluntariado não requer envolvimento regular e de longo prazo e pode ser esporádico (ONU, 2001). No Brasil, existe a Lei 9.608, promulgada em fevereiro de 2008, que regulamenta o trabalho voluntário no País, e segundo a qual, esse tipo de atividade não é remunerado, executado por pessoa física para instituição privada sem fins lucrativos ou entidades públicas de qualquer natureza, com fins culturais, de assistência social, cívicos, educacionais, científicos e recreativos (BRASIL, 1998).

Para fins de entendimento deste trabalho, foi adotada a conceituação elaborada por Cavalcante (2012), cujo estudo está alinhado a diversos trabalhos e estudos, tais como a ONU (2001), Musick e Wilson (2008), Cnaan et al. (1996), Penner (2002), a Lei 9.608/98 e sites de referências nacionais, como a Fundação Abrinq e o Portal de Voluntários e que afirma que o trabalho voluntário:

[...] é atividade onde um indivíduo doa seu tempo ou conhecimento, e com as seguintes características: pode ter ganhos financeiros, limitados ao custo de executar essa atividade; de decisão individual, mesmo que estimulado a fazer a tarefa; que permite receber benefícios, mentais ou físicos; de natureza eventual ou permanente; e que pode ou não ser executado sob as orientações de uma organização (CAVALCANTE, 2012, p.45)

A partir dessas acepções, é pertinente diferenciar esse trabalho do que é considerado formal. Azevedo (2007), Trigueiro (2010) e Cavalcante (2012) elencam alguns contrapontos a esse respeito. Como já afirmado, a principal característica marcante é em relação à remuneração. Citada em todas as conceituações sobre trabalho voluntário empregadas neste trabalho, é unânime a característica que versa sobre a não remuneração ou remuneração inferior à oferecida no mercado de trabalho

Estudos do CEPE [ISSN 1982-6729]. Santa Cruz do Sul, n. 46, p. 166-183, jul./dez. 2017. https://online.unisc.br/seer/index.php/cepe/index 
formal. O contraponto é justamente o fato de que o trabalho formal tem como principal característica a recompensa monetária pela oferta do trabalho ou serviço.

No que tange ao tempo disponibilizado, o voluntário doa seu tempo ou conhecimento somente algumas horas por semana, em torno de quatro horas, já no trabalho formal, a carga horária é de, em média, 40 horas semanais. Assim, como o trabalho voluntário não requer longas jornadas, o voluntário poderá fazer parte de várias organizações não governamentais simultaneamente ou trabalhar formalmente e voluntariar ao mesmo tempo (CAVALCANTE, 2012). O recrutamento também é diferenciado: no trabalho voluntário, é comumente informal, ao passo que, no trabalho formal, geralmente se utilizam procedimentos técnicos (AZEVEDO, 2007; CAVALCANTE, 2012; TRIGUEIRO, 2010).

Uma última característica diz respeito à aceitação das normas e dos valores organizacionais: no trabalho voluntário, é frequente a não adequação aos padrões e aos modelos propostos pela organização, fator obrigatório para os que realizam o trabalho formal (CAVALCANTE, 2012). Esses contrapontos são necessários, com o intuito de esclarecer que, para grupos com características tão heterogêneas, não é adequado o uso de teorias que foram desenvolvidas levando em consideração apenas as características dos vínculos formais de trabalho.

\subsection{Motivação e voluntariado}

Motivação é um tema constante nos estudos sobre organizações. Os estudos de Maslow, Herzberg e Vroom são apenas alguns exemplos de teorias sobre o tema reconhecidas e consagradas, mas que não podem ser aplicadas para se entender a motivação no contexto do voluntariado, devido às diferenças existentes entre o trabalho voluntário e o trabalho formal (CAVALCANTE, 2012).Ferreira et al. (2008) dizem que os estudos sobre indivíduos profissionalizados não podem ser aplicados aos voluntários, porquanto há divergências entre os dois grupos de trabalhadores que dizem respeito aos contrapontos já citados, quais sejam: as questões de remuneração e de tempo disponibilizado, o tipo de recrutamento, a aceitação ou não de normas e valores organizacionais, entre outros.

A motivação é um fator importante para o recrutamento, para o processo de identificação dos voluntários com as organizações/causa e para que permaneçam nas organizações, já que a motivação dos voluntários é diferente da que é gerenciada no primeiro e no segundo setores. No caso do trabalho voluntário, nosso foco, segundo Salazar, Silva e Fantinel (2015), existem particularidades típicas em relação ao que motiva um indivíduo a fazer parte de um grupo para ajudar a outras pessoas. Em sentido semelhante, Oliveira e Bezerra (2007) afirmam que:

\footnotetext{
A motivação é um aspecto essencial no trabalho com voluntários. Captar, assimilar e manter voluntários que desempenhem suas tarefas participando do desenvolvimento da organização com compromisso é o desafio da gestão de voluntários que, diferentemente da gestão do setor público e privado, não tem a remuneração como fator de permanência e recompensa pelo trabalho prestado (OLIVEIRA e BEZERRA, 2007, p.06).
}

Nessa lógica, há modelos específicos que dizem respeito ao contexto do voluntariado, como o Inventário das Funções do Voluntário (VFI), de Clary et al. (1998); os quatro Motivos de Batson e o

Estudos do CEPE [ISSN 1982-6729]. Santa Cruz do Sul, n. 46, p. 166-183, jul./dez. 2017. https://online.unisc.br/seer/index.php/cepe/index 
modelo do Voluntariado Contínuo de Penner. Para este estudo, foi utilizado o modelo criado por Cavalcante (2012), que é composto de quatro fases, que objetivam identificar, quantitativamente, as fases de pré-entrada, de pós-efetiva entrada (até um ano de atuação), as de permanência (após um ano de atuação) e as de saída, e de instrumentos de coleta de dados, que diagnosticam a motivação dos voluntários através de uma série de variáveis que formam cinco fatores (o altruísta, o afetivo, o amigável, o ajustado e o ajuizado).

Para as três primeiras fases (expectativas, motivações de entrada e permanência), são elencados cinco fatores de motivação que variam de altruísta a ajuizado; e para a quarta - motivos para sair da atividade voluntária - são elencados motivos que justifiquem a saída e são reunidos em três fatores: saída por escassez de recurso, saída por motivos religiosos e saída por motivos pessoais. Neste estudo, utilizamos apenas as fases referentes às motivações de expectativa e de entrada.

Esse modelo específico foi escolhido pelo fato de já ser validado em contexto nacional e regional (Nordeste brasileiro) e por ter fatores bem definidos e robustos, como foi verificado depois de sucessivas aplicações nos trabalhos de Ageu (2015), Aquino (2015), Lemos (2016), entre outros.

\section{METODOLOGIA}

Este estudo tentou deduzir, através do modelo desenvolvido por Cavalcante (2012), as motivações dos voluntários que atuam na Fundação Cidade Viva. Para esse fim, foi empregada uma abordagem quantitativa. O objetivo foi coletar opiniões a respeito das motivações dos candidatos a voluntariar e dos que ingressaram recentemente na Fundação Cidade Viva e descrever as características sociodemográficas desses grupos que pudessem, de algum modo, relacionar-se com os construtos. Assim, a pesquisa se enquadra como descritiva. Esse tipo de levantamento permite, segundo Gil (1999), através da interrogação e do questionamento às pessoas, objetivar o conhecimento e compreender comportamentos.

Para este estudo, foram utilizadas duas fases do modelo: 'expectativas' e 'entrada'. A fase 'expectativas' é aquela em que se identificam as motivações dos indivíduos que estão a um passo de iniciar o voluntariado, e a fase 'entrada' diz respeito aos que têm até um ano de permanência na atividade. A diferença foi arbitrada pelo próprio autor do modelo, e na análise confirmatória realizada, as fases distintas apresentaram níveis muito bons de validade e de confiabilidade.

Os dados foram coletados por meio de questionários (anexos A e B) adaptados de Cavalcante (2012) e advindos da aplicação presencial com candidatos e voluntários da instituição. Para a primeira fase, foram coletadas respostas dos indivíduos participantes de uma reunião específica que ocorre na instituição com os candidatos ao voluntariado, ocorrida em 30 de maio de 2015. Para a coleta relacionada à segunda fase, as respostas foram colhidas durante os meses de março e maio de 2013, em reuniões previamente agendadas com cada ministério que foi possível acessar.

Para a análise que segue, foram manipuladas duas amostras: uma relativa à fase 'expectativas', com 82 candidatos ao trabalho voluntário na Fundação, e outra de 65 voluntários

Estudos do CEPE [ISSN 1982-6729]. Santa Cruz do Sul, n. 46, p. 166-183, jul./dez. 2017. https://online.unisc.br/seer/index.php/cepe/index 
relativa à fase 'entrada', alocados em sete grupos/Ministérios da instituição que realizam o trabalho voluntário há pelo menos um ano.

Os questionários apresentados aos respondentes continham escalas do tipo likert, cada uma com vinte e uma assertivas, e cujas respostas variaram de 1 a 10. Além disso, contemplavam questões referentes a aspectos sociodemográficos e relacionais, como sexo, idade, renda, estado civil, grau de escolaridade, se tinham familiar ou amigo voluntário, etc. Esses indicadores auxiliaram a descrever o perfil e possibilitaram o entendimento de alguns dados extraídos das amostras da pesquisa.

A amostragem do primeiro grupo é de natureza aleatória simples. Nesse tipo de amostra, a escolha de um indivíduo é feita ao acaso, e cada membro da população tem igual chance de ser selecionado; já a do segundo grupo é do tipo conglomerado, visto que, nesses conjuntos, a unidade de amostragem não é mais o indivíduo, porém um grupo previamente identificado, como são os grupos/Ministérios da Fundação Cidade Viva (MARCONI e LAKATOS, 2011). Posteriormente à coleta, os dados foram alocados na planilha Excel e analisados através de recursos e técnicas estatísticas. As técnicas utilizadas neste trabalho são de natureza descritiva. Dentre elas, foi dada preferência para a média, o desvio-padrão e o coeficiente de variância.

\section{APRESENTAÇÃO DOS RESULTADOS, DISCUSSÃO E ANÁLISE DOS DADOS}

Para o processo de apresentação e de discussão dos resultados, eles foram alocados em duas seções: (1) as expectativas dos candidatos para voluntariarem na Fundação Cidade Viva e (2) a identificação dos motivos que os levaram a entrar nesse tipo de atividade. Em cada uma das seções, é apresentado o perfil médio dos respondentes e analisados, fator a fator, os índices que indicam as motivações dos grupos pesquisados.

\subsection{Motivações dos candidatos a voluntários na Fundação Cidade Viva}

$\mathrm{Na}$ fase 'Expectativa', explica-se o que as pessoas esperam da atividade voluntária, antes de iniciá-la efetivamente, para identificar, o que move os indivíduos a realizá-la. Nesta pesquisa, a amostra dos candidatos foi predominantemente feminina, com idade média de 32 anos. A respeito do estado civil, os solteiros são a maioria e representam $45,12 \%$ da amostra pesquisada; alto também é o percentual de casados - de 39,02\%. A respeito da formação acadêmica, foi verificado alto nível de escolaridade, tendo em vista que $76,82 \%$ da amostra cursam ou concluíram graduação e até mesmo são pós-graduados.

Os estudos de Musik e de Wilson (2008) delinearam tendências sociodemográficas gerais de voluntários norte-americanos. Seguindo a mesma tendência encontrada em seus estudos, o perfil médio dos candidatos a voluntários da fundação Cidade Viva é de mulheres, solteiras e cuja faixa etária é de 35 a 44 anos e com alto nível de escolarização.

Estudos do CEPE [ISSN 1982-6729]. Santa Cruz do Sul, n. 46, p. 166-183, jul./dez. 2017. https://online.unisc.br/seer/index.php/cepe/index 
Sobre a renda familiar, o estudo apontou uma variação de $R \$ 1.200,00$ a $R \$ 21.000,00$, explicada pelo alto desvio-padrão de $\mathrm{R} \$ 5.262,37$. Assim, a remuneração mensal não é uma variável que diferenciaria os sujeitos pesquisados na expectativa de se tornarem voluntários.

Em relação à ocupação dos respondentes, 69,50\% disseram que exercem alguma atividade profissional. Infere-se, portanto, que o exercício de uma profissão, de fato, não é incompatível com a realização de trabalho voluntário. Esse dado é reforçado por pesquisas anteriores que constataram uma peculiaridade do trabalho voluntário - a de que ele requer, em média, apenas quatro horas de dedicação semanal (AZEVEDO, 2007; TRIGUEIRO, 2010).

No que diz respeito à realização dessa espécie de trabalho por familiares ou amigos, apurouse que $60,97 \%$ dos respondentes têm familiares que realizam ou realizaram trabalho voluntário na fundação, e 75,61\% responderam afirmativamente para amigos. Assim, entende-se que, quando pessoas próximas atuam em atividades voluntárias, esse tipo de vínculo se caracteriza como influenciador para os candidatos a voluntariar. Essa ideia também está exposta em Musick e Wilson (2008), que discorrem a respeito de como a comunidade influencia esse tipo de decisão. A respeito de participação anterior em outro trabalho voluntário, $57,31 \%$ da amostra responderam positivamente, o que indica uma relação levemente positiva entre trabalhos voluntários anteriores e a expectativa de continuar voluntariando.

Outros dados demonstraram que apenas $14,63 \%$ dos componentes da amostra já trabalham como voluntários em outra instituição, o que denota pouca disposição para voluntariar em mais de uma organização por vez. Além disso, para $63,41 \%$ dos respondentes, o estímulo para iniciar um trabalho voluntário pode compreender a vontade de prestar auxílio ao próximo e por motivos religiosos; já para 70,73\%, a decisão é pessoal na busca por voluntariar. Para analisar as motivações, o momento 'expectativas' contemplou cinco constructos, que vão desde o altruísta até o ajuizado, exibidos no quadro a seguir:

Tabela 1 - Medidas descritivas: perfil motivacional da fase Expectativas

\begin{tabular}{|l|l|l|l|l|l|l|l|}
\hline Perfil & Questão & $\begin{array}{l}\text { Média da } \\
\text { questão }\end{array}$ & $\begin{array}{l}\text { Desvio- } \\
\text { padrão da } \\
\text { questão }\end{array}$ & $\begin{array}{l}\text { Coeficiente } \\
\text { de } \\
\text { variância } \\
\text { da questão }\end{array}$ & $\begin{array}{l}\text { Média do } \\
\text { perfil }\end{array}$ & $\begin{array}{l}\text { Desvio- } \\
\text { padrão } \\
\text { do perfil }\end{array}$ & $\begin{array}{l}\text { Coeficiente } \\
\text { de } \\
\text { variância } \\
\text { do perfil }\end{array}$ \\
\hline Altruísta & 1 & 9,94 & 0,23 & $2,35 \%$ & 9,36 & 1,31 & $13,98 \%$ \\
& 2 & 8,88 & 1,87 & $21,06 \%$ & & & \\
& 3 & 9,68 & 0,57 & $5,93 \%$ & & & \\
& 4 & 8,87 & 1,62 & $18,26 \%$ & & & \\
& 5 & 9,50 & 0,99 & $10,45 \%$ & & & \\
\hline Afetivo & 6 & 8,02 & 2,18 & $27,16 \%$ & 8,83 & 1,75 & $19,81 \%$ \\
& 7 & 8,41 & 1,90 & $22,63 \%$ & & & \\
& 8 & 9,79 & 0,44 & $4,54 \%$ & & & \\
& 9 & 9,18 & 1,32 & $14,38 \%$ & & & \\
\hline
\end{tabular}




\begin{tabular}{|l|l|l|l|l|l|l|l|}
\hline Amigável & 10 & 8,30 & 1,81 & $21,76 \%$ & 8,29 & 1,84 & $22,20 \%$ \\
& 11 & 8,21 & 1,94 & $23,68 \%$ & & & \\
& 12 & 8,60 & 1,72 & $19,99 \%$ & & & \\
& 13 & 8,05 & 1,88 & $23,31 \%$ & & & \\
\hline Ajustado & 14 & 7,99 & 2,00 & $25,00 \%$ & 8,61 & 1,70 & $19,78 \%$ \\
& 15 & 8,77 & 1,66 & $18,88 \%$ & & & \\
& 16 & 8,91 & 1,45 & $16,32 \%$ & & & \\
& 17 & 8,80 & 1,51 & $17,21 \%$ & & & \\
\hline Ajuizado & 18 & 4,20 & 3,25 & $77,53 \%$ & 5,03 & 3,41 & $67,84 \%$ \\
& 19 & 3,87 & 3,01 & $77,74 \%$ & & & \\
& 20 & 6,99 & 3,23 & $46,28 \%$ & & & \\
& 21 & 5,45 & 3,44 & $63,03 \%$ & & & \\
& 22 & 4,63 & 3,25 & $70,11 \%$ & & & \\
\hline
\end{tabular}

Fonte: Dados da pesquisa - Elaborado pelos autores.

A média do perfil 'altruísta' de 9,36 é alta. Observa-se, também, que as respostas da amostra para o perfil são bastante homogêneas, devido aos valores ínfimos do desvio-padrão $(1,31)$ e do coeficiente de variância (13,98\%). O perfil 'altruísta' aparece frequentemente associado a altos índices, quando são estudadas as motivações de voluntários, como os estudos de Souza et al. (2006). Comportamento semelhante é encontrado desde os estudos de Vroom (1964, apud ANDERSON e MOORE, 1978, p. 123), que sugerem que, embora os indivíduos possam ser motivados por várias razões específicas, eles percebem sua atividade, principalmente como "contribuir para a felicidade e o bem-estar de seus semelhantes".

Uma elevada média altruísta pode indicar, segundo Cavalcante (2012, p. 64), que a decisão de voluntariar 'aparece fortemente relacionada com o desejo de promover o bem-estar, por convicção política ou religiosa, mediante doação pessoal à prática e à socialização de iniciativas que atestam qualidades humanas superiores'. Assim, pode-se inferir que, para os pesquisados, a expectativa de voluntariar na Fundação passa pelo entendimento de que o papel a ser desempenhado por eles na Cidade Viva requer renúncia e doação pessoal.

Quanto ao perfil afetivo, o estudo revelou uma média de alto valor $(8,83)$ e uma amostra relativamente homogênea, o que se deve aos índices de desvio-padrão de 1,75 e coeficiente de variância de 19,81\%. Conforme Cavalcante (2012), o fator afetivo visa descrever o comportamento vinculado à busca da cidadania na comunidade onde voluntários e beneficiários convivem.

Composto pelos indicadores 'Cumprir o dever cidadão', 'Reduzir injustiças sociais', 'Ser membro útil na comunidade em que vivo' e 'Colaborar com a melhoria social', o perfil afetivo, na fase expectativas, cujas médias foram altas', indica motivações que envolvem tipicamente um voluntário interessado em resgatar a cidadania numa perspectiva local. Portanto, pode-se relacionar o perfil afetivo às expectativas ligadas à 'contribuição social', como destacam Carvalho e Souza (2007). A alta média para o fator 'afetivo' demonstraria a vontade dos respondentes de impactar positivamente a comunidade local e de ajudar e fazer o bem aos menos necessitados. Estudos como os de 
Hakinson e Rochester (2005) e Hibbert, et al. (2003) também encontraram fatores como 'Fazer o dever cidadão', 'Ser membro útil na comunidade em que vive' e 'Colaborar com a melhoria social', que podem ser associados ao construto 'afetivo' utilizado nesta pesquisa.

Para o perfil 'amigável', observou-se uma média de valor 8,29, que é considerado alto. Também houve um desvio-padrão de 1,84, indicando certa heterogeneidade nas respostas. Todavia, $48,47 \%$ dos respondentes atribuíram valores 9 e 10. Isso significa que os motivos de expectativa para esse perfil são sobremaneira significativos para os respondentes. O perfil 'amigável', segundo autores como Ferreira et al. (2008), Clary et al. (1998) e Hackinson e Rochester (2005), indica a vontade de se afiliar a um grupo por meio da atividade voluntária. Cavalcante (2012, p. 89) assevera que:

O construto "amigável" traz como indicadores motivos vinculados à avaliação subjetiva de contribuição para o bem estar social, e de desafortunados em particular, sob uma perspectiva amistosa, em que o voluntário se sente compartilhando algo com alguém em dado espaço organizacional. Almeja afiliação a um grupo por meio da atividade voluntária.

Assim, os resultados indicam que os candidatos a voluntariar têm expectativas em relação ao grupo de que irão fazer parte e têm expectativas de que, por meio da atividade a ser desempenhada, poderão conhecer amigos e/ou fazer parte de um grupo que partilhe dos mesmos interesses, em outras palavras, aumentar o círculo social. Os estudos de Horne e Broadbridge (1994) e Anderson e Shaw (1999) encontraram em seus achados que, entre os motivos para o desempenho da atividade voluntária, está a oportunidade de encontrar pessoas e fazer amigos. Esse achado se relaciona diretamente com o entendimento do construto amigável utilizado neste trabalho.

No perfil 'ajustado', verificou-se uma média de 8,61, considerada alta e com relativa homogeneidade (desvio-padrão de 1,70). De acordo com Cavalcante (2012, p. 71), o fator 'ajustado':

\footnotetext{
[...] reúne motivos de uma forma específica de aprimoramento social não centrada em temas cruciais ou aflitivos, mas que, de alguma forma, transmitem ao voluntário a sensação de estar, simultaneamente, promovendo a si próprio e a vida do receptor sob a perspectiva da interação grupal. Busca-se o autodesenvolvimento através de ações que estimulem o intelecto via voluntariado.
}

Nesse sentido, quando grande parte da amostra assinala, em altos níveis, que concorda com afirmações como "espero aprender a lidar com pessoas", "espero aprender algo", "espero aprender novos conhecimentos/habilidades", está indicando que, entre os motivos para voluntariar, está a possibilidade de adquirir conhecimentos diversos, sem se restringir a atividades de cunho mecanicista. A idade média (32 anos) dos respondentes é um indicador que corrobora uma média alta para o fator 'ajustado', porquanto a maioria está em plena idade produtiva, e voluntariar pode ser uma das maneiras de ampliar o networking e de adquirir novas habilidades. Essa é uma das constatações a que também chegaram Anderson e Moore (1978) em sua pesquisa. Esses autores afirmam que voluntários mais jovens parecem estar mais interessados em ganhar oportunidades para o desenvolvimento e o crescimento pessoal do que os mais velhos.

O último perfil relativo às expectativas dos respondentes é o ajuizado, com viés mais egoísta e motivações vinculadas à perspectiva de autoproteção, mediada pela ideia de obter e/ou de preservar vantagens e, secundariamente, ao coletivo (CAVALCANTE, 2012, p. 64). O perfil obteve valores medianos de 5,03. O desvio-padrão e o coeficiente de variância obtiveram índices elevados:

Estudos do CEPE [ISSN 1982-6729]. Santa Cruz do Sul, n. 46, p. 166-183, jul./dez. 2017. https://online.unisc.br/seer/index.php/cepe/index 
3.41 e $67,84 \%$, respectivamente, o que indica que a amostra é bem heterogênea quando se trata do perfil 'ajuizado'.

O fator pode parecer controverso, visto que se trata de um posicionamento centrado no eu, na satisfação própria, através do trabalho voluntário, em essência, egoísta (CAVALCANTE, 2012). Porém, Mostyn (1983) e, mais recentemente, Souza et al. (2006) também retrataram a existência de comportamentos egoístas de voluntários. Acredita-se que o perfil reflete o fato de que, apesar de os voluntários quererem ajudar outras pessoas e a comunidade, eles sentem a necessidade de recompensas, ainda que imateriais, seja o reconhecimento ou a sensação de dever cumprido. Isso também pode significar que a resposta para a motivação voluntária não está nos extremos e que um gestor preparado para reforçar positivamente as motivações de seus voluntários não se preocupa somente com a essência da causa, mas também em reconhecer os voluntários. A discussão sobre a incidência de motivações egoístas e altruístas para um mesmo voluntário já foi debatida na literatura. Autores como Fischer e Schaffer (1993, p. 51) afirmam que as motivações para voluntariar podem ser contraditórias, difíceis de mensurar, e sua articulação não é necessariamente simples.

A partir do exposto, em relação às expectativas, percebe-se que as motivações altruístas são aquelas com as quais os candidatos a voluntários mais se identificaram e que o perfil que se avulta é consonante com a proposta da Fundação Cidade Viva.

\subsection{Motivações de entrada dos voluntários da Fundação Cidade Viva}

A fase 'Entrada' é aquela em que se procuram traçar os motivos que levam os voluntários a aderirem a atividade e também, explicar as razões do trabalho voluntário para aqueles que atuam nessa atividade em um período de até um ano. Neste trabalho, observou-se uma amostra equivalente para ambos os sexos, haja vista que $60 \%$ dos respondentes são do sexo feminino e $40 \%$ masculino e 43 anos a idade média. Sobre o estado civil, $53,84 \%$ da amostra declarou estar em uma união estável enquanto solteiros representam $38,46 \%$.

Quanto à formação acadêmica e ao nível de escolaridade da amostra, 83,07\% dela é graduada ou está em fase de conclusão, e $27,69 \%$, pós-graduada. Sobre a renda familiar, a renda média de $\mathrm{R} \$ 4.000,00$ foi a mais citada, e $70,76 \%$ dos respondentes exercem alguma profissão. Isso indica a possibilidade de conciliar o trabalho formal e voluntariar simultaneamente.

Descrita a amostra, passa-se para o questionário, que contemplou perguntas referentes à realização de atividade voluntária por algum familiar ou amigo próximo. De acordo com os resultados, 53,84\% dos respondentes têm ou já tiveram algum parente envolvido com atividade voluntária, e $83,87 \%$ responderam afirmativamente quando questionados sobre o exercício desse tipo trabalho por algum amigo próximo. Isso indica que o fator parental e o círculo de amizades dos indivíduos podem afetar positivamente a decisão por voluntariar. Wilson (2000) cita autores como Rosenthal et al. (1998), Segal (1993), Sundeen e Raskoff (1994), Wuthnow (1995), Flanagan et al.(1998) e Fogelman (1997) que corroboram essa ideia.

Outros dados demonstram que 64,61\% da amostra já atuou em algum trabalho voluntário, e 83,07\% só exercem o voluntariado na Fundação Cidade Viva. Os dados demonstram, também, que 
$52,45 \%$ optaram por iniciar a atividade voluntária por decisão própria, e uma última questão indicou que os motivos religiosos e a vontade de auxiliar os mais necessitados foram decisivos para exercer o trabalho voluntário $(62,79 \%$ e $27,91 \%$, respectivamente). Fernandes (1994) refere que a lógica caritativa cristã, associada ao exercício do trabalho voluntário, tem crescido nas últimas décadas no movimento evangélico. Essa assertiva ficou evidente nas respostas da amostra desta pesquisa e atesta uma espécie de relação intrínseca entre o voluntariado e a fé cristã.

Com a finalidade de conhecer as motivações para a entrada na Fundação Cidade Viva, fez-se o seguinte questionamento: "Por que entrei na Cidade Viva?". Os motivos foram enquadrados em cinco perfis/fatores/constructos, apresentados a seguir:

Tabela 2 - Medidas descritivas: perfil motivacional da fase Entrada

\begin{tabular}{|c|c|c|c|c|c|c|c|}
\hline Perfil & Questão & $\begin{array}{l}\text { Média } \\
\text { da } \\
\text { questão }\end{array}$ & $\begin{array}{l}\text { Desvio- } \\
\text { padrão da } \\
\text { questão }\end{array}$ & $\begin{array}{l}\text { Coeficiente } \\
\text { de } \\
\text { variância } \\
\text { da questão }\end{array}$ & $\begin{array}{l}\text { Média do } \\
\text { perfil }\end{array}$ & $\begin{array}{l}\text { Desvio- } \\
\text { padrão } \\
\text { do perfil }\end{array}$ & $\begin{array}{l}\text { Coeficiente } \\
\text { de } \\
\text { variância } \\
\text { do perfil }\end{array}$ \\
\hline Altruísta & $\begin{array}{l}1 \\
2 \\
3 \\
4 \\
5\end{array}$ & $\begin{array}{l}8,67 \\
7,70 \\
8,67 \\
8,57 \\
7,71\end{array}$ & $\begin{array}{l}2,26 \\
2,74 \\
1,74 \\
2,06 \\
3,15\end{array}$ & $\begin{array}{l}26,02 \% \\
35,51 \% \\
20,05 \% \\
24,06 \% \\
40,82 \%\end{array}$ & 8,25 & 2,48 & $30,07 \%$ \\
\hline Afetivo & $\begin{array}{l}6 \\
7 \\
8 \\
9\end{array}$ & $\begin{array}{l}7,35 \\
6,44 \\
7,00 \\
6,71\end{array}$ & $\begin{array}{l}3,15 \\
3,09 \\
2,74 \\
2,72\end{array}$ & $\begin{array}{l}42,83 \% \\
48,05 \% \\
39,17 \% \\
40,52 \%\end{array}$ & 6,88 & 2,93 & $42,66 \%$ \\
\hline Amigável & $\begin{array}{l}10 \\
11 \\
12 \\
13\end{array}$ & $\begin{array}{l}6,76 \\
6,19 \\
6,03 \\
5,50\end{array}$ & $\begin{array}{l}3,00 \\
3,34 \\
3,18 \\
3,33\end{array}$ & $\begin{array}{l}44,41 \% \\
53,96 \% \\
52,68 \% \\
60,53 \%\end{array}$ & 6,11 & 3,23 & $52,79 \%$ \\
\hline Ajustado & $\begin{array}{l}14 \\
15 \\
16 \\
17\end{array}$ & $\begin{array}{l}5,41 \\
6,97 \\
6,51 \\
6,64\end{array}$ & $\begin{array}{l}3,01 \\
3,06 \\
3,01 \\
3,47\end{array}$ & $\begin{array}{l}55,61 \% \\
43,95 \% \\
46,25 \% \\
52,26 \%\end{array}$ & 6,38 & 3,18 & $49,89 \%$ \\
\hline Ajuizado & $\begin{array}{l}18 \\
19 \\
20 \\
21 \\
22\end{array}$ & $\begin{array}{l}1,81 \\
2,29 \\
5,47 \\
3,17 \\
3,23\end{array}$ & $\begin{array}{l}2,49 \\
2,69 \\
3,45 \\
3,08 \\
3,21\end{array}$ & $\begin{array}{l}137,36 \% \\
117,25 \% \\
63,16 \% \\
97,22 \% \\
99,37 \%\end{array}$ & 3,27 & 3,26 & $99,24 \%$ \\
\hline
\end{tabular}

Fonte: Dados da pesquisa - Elaborado pelos autores. 
O perfil 'altruísta' obteve uma média de 8,25 , que é considerada alta, porém os altos índices de desvio-padrão e coeficiente de variância (2,48 e 30,07\%) sugerem que essa média provém de respostas bastante heterogêneas. Compreende-se, pois, que o altruísmo é importante, mas não é o primordial quanto aos motivos por que os voluntários ingressam na Fundação Cidade Viva. Fischer e Schaffer (1993, p. 43) asseveram que o fator 'altruísmo' é recorrente na maioria das pesquisas sobre motivação voluntária e só varia a intensidade.

Dos sete ministérios pesquisados, quatro apresentam atuações em locais arriscados, o que propicia uma alta média 'altruísta', porque, ainda que corram perigo, os voluntários executam suas atividades e se preocupam essencialmente com o bem do outro, como a conceituação do fator propõe. Assim, há uma consonância com as aspirações dos respondentes e os objetivos dos Ministérios da Cidade Viva, o que pode promover um exercício satisfatório do trabalho voluntário e, por conseguinte, uma atuação permanente.

O perfil 'afetivo' apresentou média moderada de 6,88 e com índices relevantes de desvio padrão e coeficiente de variância: 2,93 e 42,66\%, respectivamente. Ainda assim, compreende-se que resgatar a cidadania dos necessitados socialmente (idosos, crianças e pacientes hospitalizados) é, na visão dos respondentes, foi fator motivacional importante para que o trabalho voluntário na Cidade Viva fosse iniciado. Autores como Gouveia (2003) entendem que as pessoas que aderem ao trabalho voluntário tendo essa motivação como imperativa reconhecem o outro (o beneficiário) como igual e que ele também deve ter uma vida social digna. Estudos como o de Hibbert et al. (2003) identificaram motivações voluntárias mais coletivistas que podem ser associadas ao perfil afetivo, tendo em vista que a atuação dos voluntários nos ministérios está diretamente relacionada a esse tipo de assistência. Exemplo disso são os voluntários atuantes nos Ministérios 'Criança Viva', 'Esperança Viva' e 'Restaurando Viva'. Dos sete que compõem essa amostra, foram os que atribuíram valores de maior significância para esse perfil.

O terceiro perfil, o "amigável”, também obteve uma média que é considerada moderada: 6,11, e assim como no perfil anterior, foi verificado que se trata de uma amostra heterogênea, tendo em vista o expressivo valor do coeficiente de variância (52,79\%). Todavia, 30\% da amostra atribuiu valores 9 e 10 a esse perfil, e $43 \%$ conferiram os valores 8,9 e 10, o que demonstra que o fator amigável também é relevante quando tratamos das motivações de entrada de nossos respondentes. Pesquisas como as de Horne e Broadbridge (1994), Anderson e Shaw (1999) e Hakinson e Rochester (2005) também encontraram a indicação de motivos relacionados ao construto amigável.

Posto isso, infere-se que os voluntários da amostra deste trabalho, no ano inicial do trabalho voluntário na Fundação Cidade Viva, procuram, ainda que não seja de modo tão expressivo, conhecer novas pessoas, fazer parte de um grupo e aumentar o círculo social e maneiras de prestar auxílio aos que precisam de ajuda. Nesse sentido, ao dispor de vários Ministérios capazes de atender às aspirações iniciais dos respondentes, a Cidade Viva faz com que eles realizem a atividade voluntária mais satisfatoriamente, garantindo melhores resultados para os que são atendidos por esses grupos.

O perfil 'ajustado', que trata da sensação de estar, simultaneamente, promovendo a si próprio e a vida do receptor, sob a perspectiva da interação grupal e da busca de autodesenvolvimento

Estudos do CEPE [ISSN 1982-6729]. Santa Cruz do Sul, n. 46, p. 166-183, jul./dez. 2017. https://online.unisc.br/seer/index.php/cepe/index 
através do voluntariado, também apresentou média moderada de valor 6,38. Isso indica uma tendência de que, embora não recebam aportes financeiros para desempenhar suas atividades, os voluntários gostariam de ser recompensados de algum modo por seu trabalho. Uma dessas maneiras consiste em adquirir novos conhecimentos e voluntariar. Em suas pesquisas, Anderson e Moore (1978) chegam a conclusões que corroboram a ideia ora apresentada. Acredita-se que, devido à diversidade e à pluralidade de Ministérios da instituição, muitas possibilidades de atuação são oferecidas, o que propicia aprendizados diversos.

O Ministério 'Integração', no qual existe a possibilidade de aprender novas formas de se conversar e de fazer trabalho em equipe, e 'Esperança Viva', onde é possível desenvolver habilidades de comunicação, de responsabilidade e comprometimento social, são exemplos que se encaixam no perfil 'ajustado'. Foram os participantes desses ministérios que atribuíram maiores médias a esse fator.

O perfil 'ajuizado' tem um viés essencialmente egoísta e apresentou média baixa, expressa pelo valor de 3,27. O coeficiente de variância, altíssimo, de valor 99,24\%, denota uma amostra extremamente heterogênea, ou seja, indica uma grande oscilação de respostas em relação à média. Contudo, nesse perfil, o percentual de respostas com valores menores (1, 2, 3 e 4) foi prevalente, porquanto correspondeu a $69 \%$ da amostra. Entende-se que, mesmo que essa média seja baixa, levando em consideração a literatura de autores como Mostyn (1983) e Souza et al. (2006), os motivos com viés mais egoísta e vinculados ao ego estão fortemente presentes em pesquisas realizadas acerca da atividade voluntária.

Compreende-se que, apesar de uma variação tão grande de respostas, o perfil dessas pessoas é benevolente e direcionado a atitudes de apoio aos menos favorecidos. Logicamente, não se podem desconsiderar os altos índices de variação. Como já citado, tanto para quem tem expectativas de voluntariar quanto para aqueles cujas motivações de entrada foram avaliadas, os altos índices de variância indicam que não é uma resposta simplista ou reducionista, o que se encontra quando se fala de motivação voluntária. E o que pode aparentemente parecer controverso nada mais é do que um reflexo da complexidade humana. Pessoas são egoístas e altruístas ao mesmo tempo, e entender qual desses fatores pesa mais na motivação é fator crucial na tomada de decisões dos gestores.

Em relação à assertiva 20: 'Entrei na Cidade Viva para sentir-me melhor como pessoa', houve uma média de 5,47 , que divergiu das demais desse perfil. Os voluntários deste estudo conferiram valores mais significativos a essa afirmação, devido ao fato de o trabalho voluntário proporcionar essa sensação de melhoria pessoal. Em outras palavras, pode-se considerar o trabalho voluntário como um meio/consequência para se ter a sensação de evolução humana e pessoal. Isso demonstra convergência com a definição sobre o trabalho voluntário de Cavalcante (2012) adotado neste estudo, quando afirma que o trabalho voluntário proporciona benefícios, não necessariamente materiais ou financeiros, aos voluntários.

Estudos do CEPE [ISSN 1982-6729]. Santa Cruz do Sul, n. 46, p. 166-183, jul./dez. 2017. https://online.unisc.br/seer/index.php/cepe/index 


\section{CONSIDERAÇÕES FINAIS}

Este estudo reforça a posição de que, apesar de o tema nele abordado ser constante na literatura, os estudos sobre motivação voluntária ainda são incipientes, visto que pesquisas que são desenvolvidas para ambientes empresariais comuns não devem ser aplicados a essa população devido às importantes diferenças que existem entre esses dois grupos de trabalhadores.

Acredita-se que a motivação é um dos aspectos mais importantes no trato das questões relacionadas ao trabalho voluntário, porquanto a gestão correta de fatores como os apresentados neste trabalho pode melhorar problemas comumente encontrados em grupos de trabalhadores voluntários, como abandono e rotatividade.

É importante frisar que, para a maioria dos sujeitos desta pesquisa, o fato de exercerem alguma atividade profissional formal não impede que atuem em trabalhos voluntários. Em outras palavras, o fator escassez de tempo não é impedimento para a realização de trabalho voluntário.

Ainda que tenham sido encontrados altos índices para o construto 'altruísta' no conjunto de resultados e que é sobremaneira importante disseminar mensagens centradas no construto mais sobressalente, é preciso atentar para o fato de que os demais perfis também apresentaram indicadores com níveis expressivos que apontam que outras motivações relevantes devem ser consideradas, como os perfis 'afetivo', 'amigável' e 'ajustado', por exemplo. Até mesmo para o fator 'ajuizado', para o qual foram encontrados os menores índices, não é recomendado que seja ignorado, por causa dos altos índices de variação encontrados.

Assim, a veiculação de conteúdo relativo aos fatores pode e deve seguir uma ordem de precedência, mas nenhuma das motivações deve ser totalmente desconsiderada. $E$ tanto o folheto interno "Bússola", no endereço eletrônico da Fundação, quanto às celebrações religiosas podem ser, não exclusivamente, meios de disseminar eficazmente um discurso que considere os fatores de motivação aqui mencionados. Além disso, programas de valorização poderão ser implantados, com o intuito de estimular e reconhecer a importância do voluntário para a Fundação e para os que são atendidos por eles, visando a uma atuação contínua.

Ter ciência do que motiva cada grupo - especificamente os pretensos voluntários e os voluntários permanentes - é útil, do ponto de vista de gestão, porque, para cada grupo específico, o conhecimento das motivações distintas pode levar a decisões gerenciais direcionadas, seja na fase de recrutamento seja na de sedimentação da permanência dos sujeitos.

Em relação às suas limitações, o estudo apontou que são escassas as publicações recentes em relação ao tema, o que requer estudos descritivos para que se compreenda bem mais a realidade social que ora se apresenta, e a dificuldade de se apreender com um instrumento quantitativo toda a subjetividade envolvida nos processos motivacionais dos indivíduos. É importante salientar que, apesar dessas limitações, entende-se que, em comparação com estudos semelhantes a esta pesquisa, há um bom nível de descrição das motivações.

Para futuras pesquisas, sugere-se que seja aplicada a totalidade do instrumento de coleta de dados, incluindo outras fases além das já citadas neste estudo, objetivando analisar possíveis variações das razões desses indivíduos. Por fim, deve-se replicar o instrumento em organizações não

Estudos do CEPE [ISSN 1982-6729]. Santa Cruz do Sul, n. 46, p. 166-183, jul./dez. 2017. https://online.unisc.br/seer/index.php/cepe/index 
religiosas, com vistas a estudos comparativos por meio dos quais seja possível traçar um perfil mais amplo de generalista do voluntariado no Brasil.

\section{REFERÊNCIAS}

AGEU, J. D. Motivações de permanência no trabalho voluntário: um estudo na Fundação Cidade Viva João Pessoa-PB. 2015. 91 f. Dissertação (Mestrado em Administração) - Programa de Pósgraduação em Administração, Universidade Federal da Paraíba, João Pessoa, 2015.

ANDERSON, J. C.; MOORE, L. F. The Motivation to volunteer. Journal of Voluntary Action Research, 7, p. 120-129, 1978.

ANDERSON, M. J.; SHAW, R. N. A comparative evaluation of qualitative data analytic techniques in identifying volunteer motivation in Tourism. Tourism Management, v. 20, n. 1, p. 99-106, 1999.

ANHEIER, H. K. Nonprofit organizations: theory, management, policy. London: Routledge, 2005.

AQUINO, M. A. G. Expectativas, adesão e desligamento no trabalho voluntário: estudos de motivos do voluntariado da Fundação Cidade Viva, João Pessoa-PB. 2014. 126 f. Dissertação (Mestrado em Administração) - Programa de Pós-graduação em Administração. Universidade Federal da Paraíba, João Pessoa, 2015.

AVRITZER, L. Sociedade civil e participação no Brasil democrático. In: AVRITZER, L. (Org.). Experiências nacionais de participação social. Belo Horizonte: Cortez, 2010. 7-12 p.

AZEVEDO, D. C. Voluntariado Corporativo: motivações para o trabalho voluntário. In: XXVII Encontro Nacional de Engenharia de Produção, Anais... Foz do Iguaçu/PR, 2007.

BRASIL, Presidência da República. LEI № 9.608, de 18 de fevereiro de 1998. Brasília, 1998. Disponível em: www.planalto.gov.br/ccivil_03/leis/L9608.htm. Acesso em: 02 jan. 2013.

CARVALHO, V. D.; SOUZA, W. J. Pobres no ter, ricos no ser: trabalho voluntário e motivação na Pastoral da Criança. Rev. adm. Contemp., Curitiba, v. 11, n. 2, jun, 2007. Disponível em: $<$ http://www.scielo.br/scielo.php?script=sci_arttext\&pid=S1415-65552007000200007\&lang=pt>.

Acesso em 15 nov. 2015.

CAVALCANTE, C. E. Motivação no trabalho voluntário: expectativas e motivos na Pastoral da Criança. Tese (Doutorado) - Programa de Pós-graduação em Administração. Universidade Federal do Rio Grande do Norte, Natal, 2012.

Motivação no trabalho voluntário: delineamento de estudos no Brasil. Rev. Estudos do CEPE (UNISC), v. 38, p. 161-182, 2013a.

CIDADE VIVA, Fundação. Disponível em: <cidadeviva.org>. Acesso em: 10 dez. 2015.

Godstock. Disponível

em:

<http://cidadeviva.org/godstock/2015/wpcontent/uploads/2015/10/Release-Godstock-2015.pdf> Acesso em: 15 dez. 2015.

CLARY, E. G.; SNYDER, M.; RIDGE, R.; COPELAND, J.; STUKAS, A. A.; HAUGEN, J.; MIENE, P. Understanding and assessing the motivation of volunteers: a functional approach. Journal of Personality and Social Psychologisty, 74, 1516-1530, 1998.

CNAAN, R. A.; HANDY, F.; WADSWORTH, M. Defining who is a volunteer: conceitual and empirical considerations. Nonprofit and Voluntary Sector Quarterly, 25 (3), p. 364-383, 1996.

CHAPMAN, G.; WHITE P. As características singulares do ambiente do voluntariado. In: As cinco linguagens de valorização pessoal no ambiente de trabalho. São Paulo: Mundo Cristão, 2012.

Estudos do CEPE [ISSN 1982-6729]. Santa Cruz do Sul, n. 46, p. 166-183, jul./dez. 2017. https://online.unisc.br/seer/index.php/cepe/index 
Disponível

em: <http://books.google.com.br/books?id=X9qtBZXjEbQC\&pg=PT167\&dq=trabalho+volunt\%C3\%A1 rio+e +rotatividade\&hl=pt-BR\&sa=X\&ei=XulwUdryH PROwGs14CQBQ\&sqi=2\&ved =0CC8Q6AEwAA>. Acesso em: 11 fev 2016.

COSTA, S. F. Gestão de pessoas em instituições do terceiro setor: uma reflexão necessária. Terra e Cultura, ano XVIII, oㅡ 35, p. 40-58, Londrina, julho/dezembro de 2002. Disponível em: http://web.unifil.br/docs/revista_eletronica/terra_cultura/35/Terra\%20e\%20Cultura_35-4.pdf. Acesso em: 11 fev 2016

DRUCKER, P. F. Administrando em tempos de grandes mudanças. São Paulo: Pioneira, 1999.

FERNANDES, R. C. Privado porém público: o terceiro setor na América Latina. Rio de Janeiro: Relume-Dumará, 1994.

FERREIRA, M.; PROENÇA, T.; PROENÇA, J. F. As motivações no trabalho voluntário. Rev. Portuguesa e Brasileira de Gestão, v. 7, n. 3, p. 43-53, 2008.

FISCHER, L. R.; SCHAFFER, K. B. Older volunteers: a guide to research and practice. London: Sage, 1993.

GIL, A. C. Métodos e técnicas de pesquisa social. São Paulo: Atlas, 1999.

GOUVEIA, V. V. A natureza motivacional dos valores humanos: evidências acerca de uma nova tipologia. Estud. psicol. (Natal) [online], v. 8, n. 3, p. 431-443, 2003. ISSN 1413-294X.

HANKINSON, P.; ROCHESTER, C. The Face and the Voice of Volunteering: A Suitable Case for Branding? International Journal of Nonprofit \& Voluntary Sector Marketing, v. 10, n. 2, 93-105, 2005.

HIBBERT, S.; PIACENTINI, M.; ALDAJANI, H. Understanding Volunteer Motivation for Participation in a Community-Based Food Cooperative. International Journal of Nonprofit and Voluntary Sector Marketing, 8(1), 30-42, 2003.

HORNE, S.; BROADBRIDGE, A. The Charity Shop Volunteer in Scotland: Greatest Asset or Biggest Headache?. Voluntas International Journal of Voluntary and Non-profit Organizations, v. 5, n. 2, p. 205-218, 1994.

IBGE. As fundações privadas e associações sem fins lucrativos no Brasil - 2010. Rio de Janeiro: IBGE, 2012.

LANDIM, L., SCALON, M. C. Doações e trabalho voluntário no Brasil - uma pesquisa. Rio de Janeiro: 7 Letras, 2000.

LEMOS, S. L. L. Motivação para expectativa, entrada, permanência e saída: um estudo longitudinal no voluntariado da Fundação Cidade Viva. 2016. 129f. Dissertação (Mestrado em Administração) Programa de Pós-graduação em Administração, Universidade Federal da Paraíba. João Pessoa, 2016.

MARCONI, M. A.; LAKATOS, E. V. Técnicas de pesquisa. São Paulo: Atlas, 2011.

MOSTYN, B. The meaning of volunteer work: a qualitative investigation. In: HATCH, S. (org) Volunteers: patterns, meanings \& motives. Hertz (Reino Unido): The Volunteer Centre, 1983.

MUSICK, M. A.; WILSON, J. Volunteers: A social profle. Indiana, University Press, 2008.

OLIVEIRA, F. C. de; BEZERRA, R. M. M. Fatores que geram a evasão no trabalho voluntário. Anais do XXXI Encontro da ANPAD (EnANPAD 2007). Rio de Janeiro: ANPAD, 2007. Disponível em: $<$ www.anpad.org.br>. Acesso em: 08 de Nov 2015.

Estudos do CEPE [ISSN 1982-6729]. Santa Cruz do Sul, n. 46, p. 166-183, jul./dez. 2017. https://online.unisc.br/seer/index.php/cepe/index 
ONU. Measuring volunteering: a practical toolkit. A joint project of independent sector and United Nations volunteers.In A. Dingle (ed.), United Nation, Germnay, 2001.

PENNER, L. A. Dispositional and Organizational Influences on Sustained Voluterism: An Interacionist Perspective. Journal of Social Issues, v. 58, n. 3, p. 447-467, 2002.

PICCOLI, P.; GODOI, C. K. Motivação para o trabalho voluntário contínuo: uma pesquisa etnográfica em uma organização espírita. Organizações \& Sociedade, v. 19, n. 62, p. 399-415, 2012.

PROCOPIUCK, M.; MEYER JR, V. Gestão Estratégica em Ambiência de Trabalho Voluntário. Cadernos Gestão Pública e Cidadania. v. 16, n. 58. São Paulo: 2011.

RESS, A. P. P. de M.; MORAES, R. O.; NAKANO, D. N. O uso da gestão de conhecimento como fator de moderação do impacto da alta rotatividade da equipe de TI no desempenho dos projetos. In: XXX ENCONTRO NACIONAL DE ENGENHARIA DE PRODUÇÃO, 2010, Anais eletrônico... São Paulo/SP, 2013.2 Disponível em: http://www.abepro.org.br/biblioteca/enegep2010_TN_STO_120_783_16859.pdf. Acesso em: 25 fev de 2016.

RODRIGUES, M. C. P. Terceiro Setor: para que serve?. Conjuntura Econômica, v. 53, n. 1. p. 41-45, São Paulo: FGV, jan. 1997.

SALAMON, L. M. The rise of the Nonprofit Sector. Foreign Affairs, v. 74, n. 3, 1994.

SALAZAR, K. A.; SILVA, A. R. L.; FANTINEL, L. D. As relações simbólicas e a motivação no trabalho voluntário. Revista de Administração Mackenzie, v. 16, n. 3, p. 171-200, 2015.

SOUZA, W. J.; MEDEIROS, J. P. de; FERNANDES, C. L. Trabalho voluntário: elementos para uma tipologia. In: X Colóquio Internacional sobre Poder Local, 2006, Salvador. Desenvolvimento e Gestão Social de Território. Salvador: NPGA. São Paulo: ANPAD, 2006. p. 1-16.

TACHIZAWA, T. Organizações não governamentais e terceiro setor: criação de ONGs e estratégias de atuação. 5 $5^{a}$ edição Atlas, 2012. Disponível em: Vital Source Bookshelf Online. Acesso em jan. 2016.

TEODOSIO, A. S. S. Voluntariado: entre a utopia e a realidade da mudança social. In: XXVI Encontro Nacional dos Programas de Pós-graduação em Administração - ENANPAD, 2002, Salvador. Anais... Salvador: Associação Nacional dos Programas de Pós-graduação em Administração - ANPAD, 2002. p. $1-14$.

TRIGUEIRO, R. P. C. Percepções das relações entre trabalho remunerado e trabalho voluntário: um estudo com voluntários da pastoral da criança. 2010. $101 \mathrm{f}$. Dissertação (Mestrado em Políticas e Gestão Públicas; Gestão Organizacional) - Universidade Federal do Rio Grande do Norte, Natal, 2010.

WILSON, J. Volunteering. Annu. Rev. Sociol., v. 26, n. 1, p. 215-240, 2000. 